\title{
DESIGN OF CROSS-SECTION ON ROADS THROUGH BUILT-UP AREAS
}

\author{
M. KIEĆ' 1 M. TRACZ 2 , S. GACA ${ }^{3}$
}

\begin{abstract}
The research into the use of less costly modifications of road links and networks, and changes in the service of road surroundings aimed at ensuring an improvement of through traffic performance in suburban areas, and on roads passing through built-up areas as small localities, with application of simulation model, is presented in this paper. From among possible designs, the authors investigated and presented the effectiveness of two, i.e. implementation of an additional multifunctional median lane in the road cross-section, and construction of service roads with different locations of intersections (end or middle of the road section).

The analysis is focused on the impact of such changes on traffic performance and road safety. The authors analysed travel speed, delay and share of platoon traffic on a uniform sections of the road for different types of road surroundings service. The study presents the results of analyses of road network before and after modification, and the assessment of:

- impact of access points density and level of their use on road traffic performance,

- impact of driving through road sections in built-up area on building platoon traffic,

- impact of change in the cross-section type on traffic performance.
\end{abstract}

Key words: simulation model, modification of road network, road safety, cross-section, traffic performance, measurements of effectiveness, delay, travel speed, platoon.

\section{INTRODUCTION}

The process of urban deglomeration, in which part of city populations migrate out of the city into the suburbs, caused over the last ten years an intensive development of suburbs. This has resulted in the construction of commercial and residential buildings alongside the sections of national roads carrying traffic in and out of cities. In most cases, this development took place along major roads. The localization of residential buildings, as well as commercial buildings in the immediate vicinity of major roads, without appropriate service and local roads network is a frequent phenomenon in

\footnotetext{
${ }^{1}$ Cracow University of Technology, Faculty of Civil Engineering, ul. Warszawska 24, 31-155 Kraków, Poland, e-mail: mkiec@pk.edu.pl

${ }^{2}$ Cracow University of Technology, Faculty of Civil Engineering, ul. Warszawska 24, 31-155 Kraków, Poland, e-mail: mtracz@pk.edu.pl

${ }^{3}$ Cracow University of Technology, Faculty of Civil Engineering, ul. Warszawska 24, 31-155 Kraków, Poland, e-mail: sgaca@pk.edu.pl
} 
Poland. Driveways to buildings are densely packed along such roads and their number can reach as many as 80 per kilometre, although the traffic generated by them during the day is very low. The peak of this traffic is in the mornings when the flow of traffic into town is heaviest. It causes overlapping of commuter and through traffic and leads to interruptions of traffic flow and deterioration of traffic conditions. Travel speed is reduced and greater delays extend the travel times through urban areas. This phenomenon can be encountered not only in suburban areas, where it has the most adverse consequences, but also on those sections of roads that pass through built-up areas in the localities. In Poland, ca. 30\% of the length of major roads pass through built-up areas [1]. This situation results from planning errors and poor regulations of land-use policy. Lack of adequate policies has degraded the parts of road network which had basic traffic function. This situation is further complicated by a lack of network of express roads and motorways and inadequate development of road network transformation, including construction of by-passes. One radical change would involve building a hierarchical road network, though it is a costly and long-term challenge.

Following the arguments above, the research presented here is carried out. Its aim was to find out about the possibility of using less costly modifications of road networks and changes in the service of road surroundings to ensure an improvement in the performance of through traffic in suburban areas and on roads passing through built-up areas, particularly through small localities. The investigations concern sections of roads with two-lane cross-section.

From among possible designs, the authors have chosen to investigate and present in the study the effectiveness of the following designs:

- Implemention of an additional multifunctional median lane, specially signed and marked (also with red surface) in the road cross-section,

- Construction of service roads with different locations of intersections merging traffic with the existing roads (end or middle of a section).

The analysis focused on the impacts of such changes on traffic performance and road safety. The authors analysed travel speed, delay and platoon traffic on a uniform section of the road for different scenarios of service of road surroundings. Furthermore, the study presents the results of analyses covering the evaluations of:

- impact the density of access points (density) and level of their use on road traffic performance,

- impact of driving through sections in built-up area on building platoon traffic,

- impact of change in the cross-section type on traffic performance.

\section{Methods of ReSEARCH}

In the available methods of evaluating traffic performance $[2,3]$ for two-lane roads no consideration is given in the traffic performance calculation procedures to specific features of sections passing through localities in built-up areas. However, the HCM 
2010 [3] proposed the methodology for evaluation of traffic performance including countryside roads with increased intensity of road surrounding development, also those with speed limits. The methods of estimation of traffic performance used in practice take into account either sections outside the development (rural roads) or urban sections (arterials). Roads passing through small or medium localities are substantially different mainly with regard to the surrounding development and the way it is used. Consequently, it is difficult to use the results of calculation methods or research done in this area in other countries $[4,5,6,7,8]$. The foreign bibliography quotes the results of simulation researches on arterial sections entering towns. This, however, can be used to a limited degree only for the purpose of modelling individual components of road networks such as, for example, bus stops or pedestrian crossings [5]. Few former researches on traffic performance over the sections passing through localities focused on the analysis of average speed, headways, and vehicle disturbances in the traffic flow. As it is shown in these researches, development of road surroundings is of significant effect to vehicle traffic performance while passing across small localities $[1,5,9,10,11]$. However, mainly traffic the speed analysis without such measures as delays, platoon traffic share or travel speed [12], are the focus of such research, and the access impact on traffic performance is not quantified.

Therefore, in order to analyse the effectiveness of various ways of providing access and service of road surroundings over suburban sections and roads passing through built-up areas, the simulation was employed. On the grounds of such research conducted by means of road traffic simulation program VISSIM v.5.1, variability of travel speed, delays and platoon traffic share were evaluated. VISSIM software allows users to simulate traffic flow assignment along the road sections with different cross section. The model used in the simulation program very well represents the behaviour of drivers passing small localities [13]. The analyses were conducted on an adopted model section surrounded by a development, in which the length of the passage, number of lanes, number and type of access points were represented. The analyses also took into consideration traffic volumes on the major road, and the traffic volume generated by access points.

The analysis was carried out on a selected section of the national road No 7, on that basis the simulation model was constructed [14]. The section is located in a Cracow suburban zone, and is ca. $800 \mathrm{~m}$ long, with a single carriageway cross-section and with an extra multifunctional median lane (Fig. 1). The speed limit over the section is $50 \mathrm{~km} / \mathrm{h}$, density of access points is high (47 residential driveways, 4 commercial driveways and 2 intersections without traffic signals). Due to the close neighbourhood of a city, the intense local traffic over the section in question overlaps the through traffic. The average daily volume over the analyzed section is ca. $19000 \mathrm{veh} / 24 \mathrm{~h}$, and in the peak period ca. $1400 \mathrm{veh} / \mathrm{h}$, in the road cross-section. For the purpose of simulation, the traffic volumes on the driveways and on the intersections were measured. It was found out that each residential driveway generates $\mathrm{ca} .1 \mathrm{veh} / \mathrm{h}$, and each commercial driveway generates ca. $8 \mathrm{veh} / \mathrm{h}$. For the intersections, the traffic volume in the measurements was 
provided. On the grounds of empirical survey, vehicle attributes were defined in the model, vehicle speeds in free flow (on the basis of the function of empirical speed distribution), and the type of vehicle: heavy vehicles and passenger cars. The traffic measurements used to calibrate the model were made in three cross-sections, i.e. that there was no possibility of overtaking or passing other vehicles. The majority of the model parameters were adopted as default values except the gap between vehicles; the minimum gap between vehicles ensuring the minimum braking distance of $2 \mathrm{~m}$, the speed for turning relation from $5^{\circ} \mathrm{km} / \mathrm{h}$ (for individual driveways) to $20^{\circ} \mathrm{km} / \mathrm{h}$ (for intersections) as critical gap for intersections and driveways. Default variables in the simulation model were neither studied nor calibrated. Taking into account the way of analysis, i.e. a relative assessment of changes in traffic performance between the different scenarios, this approach is sufficient. The measuring points in the model were located at the minimum of $100 \mathrm{~m}$ each, and the generation cross-sections for the major road were located outside the impact of the analyzed section. As a result of the simulation, several measures of effectiveness, such as the travel time through built-up area, as well as travel speed, delay and headways between vehicles were determined. The analyses were made for varying traffic volume levels on the major road, as the main goal was to observe the variations in the measures of traffic performance in the case of growing volume number of vehicles. Traffic volume variations ranged between $400 \div 1,600 \mathrm{veh} / \mathrm{h}$ for one direction of traffic, which is a value close to the road section capacity.

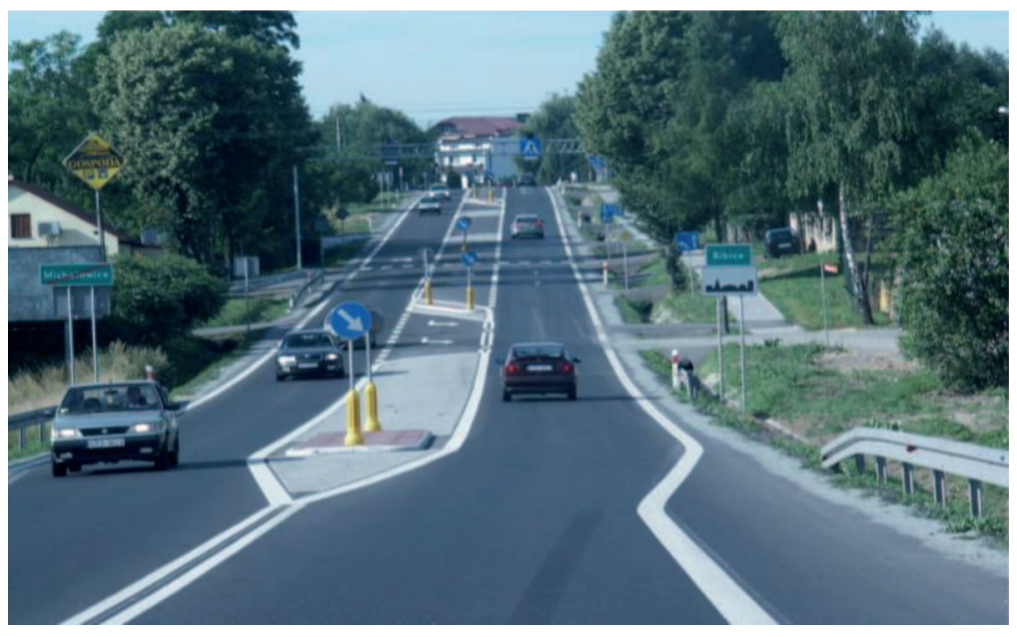

Fig. 1. View of the beginning of the model road section. Cross-section with additional multifunctional median lane. 
In the simulation research of the effectiveness of various ways to provide accessibility and services of the road surroundings, analyses were made for the following situations (Fig. 2):

scenario 0 - a cross-section with an additional multifunctional median lane for road surroundings service, and two separate additional lanes for turning left on the intersections. Lack of access control over the entire length of the analyzed section (current state).

scenario 1 - this is a design with an additional multifunctional median lane excluded to the entire length of the locality. The left turning manoeuvre is performed from the straight on lane. Separate lanes for turning left on the intersection are only on the direction with right of way. The analysis of such scenario was made in order to compare the impact of changed cross-section type on the performance of vehicle traffic. scenario 2 - elimination of the existing access points while constructing service roads along the road section in question. The traffic volume formerly generated on the driveways was directed to side entries of one intersection with shifted entries located in the centre of the locality. Additional lanes for left turning are separated on the intersection. scenario 3 - elimination of the existing access points while constructing service roads along the road section in question. The traffic volume formerly generated on the driveways was redirected by service roads to side entries of two intersections with shifted entries located on the ends of the locality. At both intersections, additional lanes for turning left were provided on the direction with right of way.

\section{Simulation Research of traffic PERformance MEASURES}

At the first step of the simulation research, the analysis was performed on the travel speed, which is the quotient of the length of the road section investigated to the time of passing it. With this aim in view, the analysis was done on the profiles of average local speed in relation to the manner of the road surroundings being serviced. On the basis of the results, speed profiles were prepared that showed variations in the local speed over the length of analysed section for various levels of traffic volume, with differentiated driving directions. Fig. 3 illustrates the speed profile for traffic volume of $1,600 \mathrm{veh} / \mathrm{h}$ for each scenario of the design of road surroundings service for one of the two directions analyzed. The highest values of local speeds appear in scenario 3 , and are as high as $60 \mathrm{~km} / \mathrm{h}$, which is even over $15 \mathrm{~km} / \mathrm{h}$ more than in the other designs. For the other scenarios, the shapes of speed profiles are close to each other, and the local speeds achieved are small. Table 1 presents the values of travel speeds on a given road section in relation to traffic volume and the adopted version of road surrounding service. The most significant increase of travel speed, as compared with scenario 0 , is observed for the design with service roads and two intersections located on the road section ends. The average travel speed is then by $5.7 \mathrm{~km} / \mathrm{h}$ higher than in the starting scenario and by $8 \mathrm{~km} / \mathrm{h}$ higher than in scenario 
scenaria 0 ('with' an acdditional multiŕunction mediar lare)

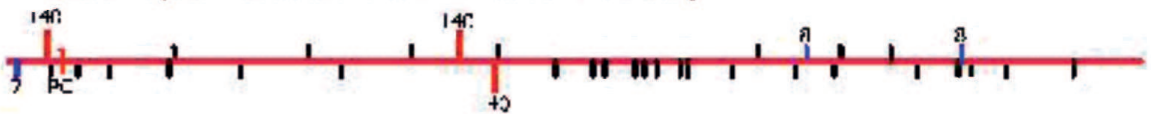



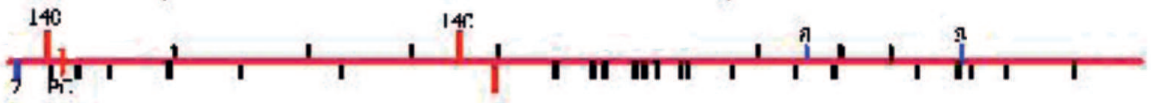

scenario 2

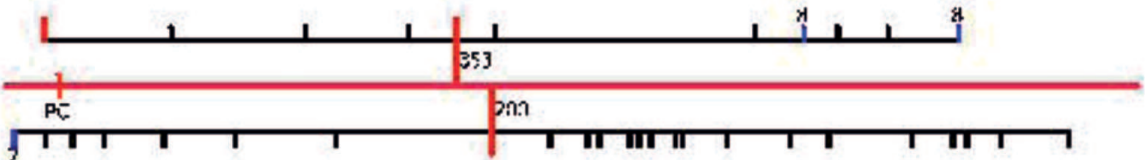

scenario 3
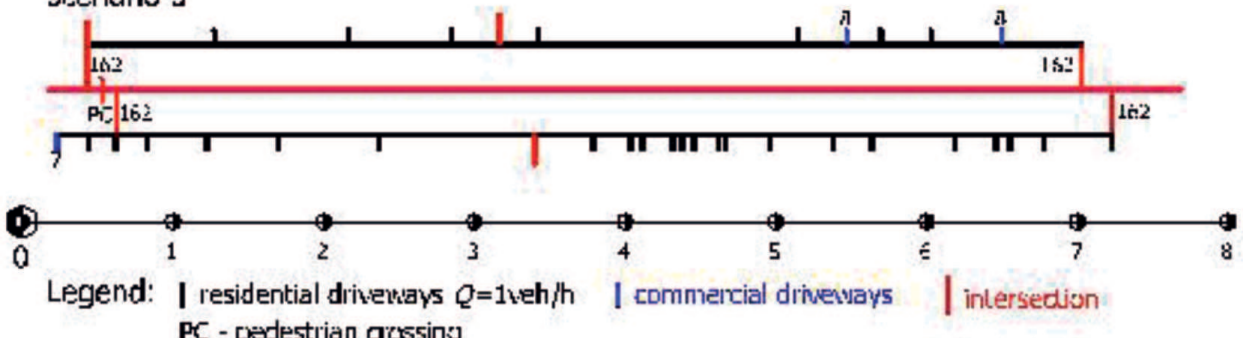

PC - pëdestrian aussino



Fig. 2. Diagrams of road network modification scenarios provided for the simulation research. View of the of the model road section [15].

1 (before reconstruction) for the traffic volume of 1,600 veh/h/lane (Fig. 4). Up to the traffic volume of ca. 1,000 veh/h/lane, the scenarios with service roads are comparable, and the travel speed is by ca. $2.2 \mathrm{~km} / \mathrm{h}$ greater than for the scenario with an additional 
multifunctional median lane. The introduction of access control significantly affects the travel speed.

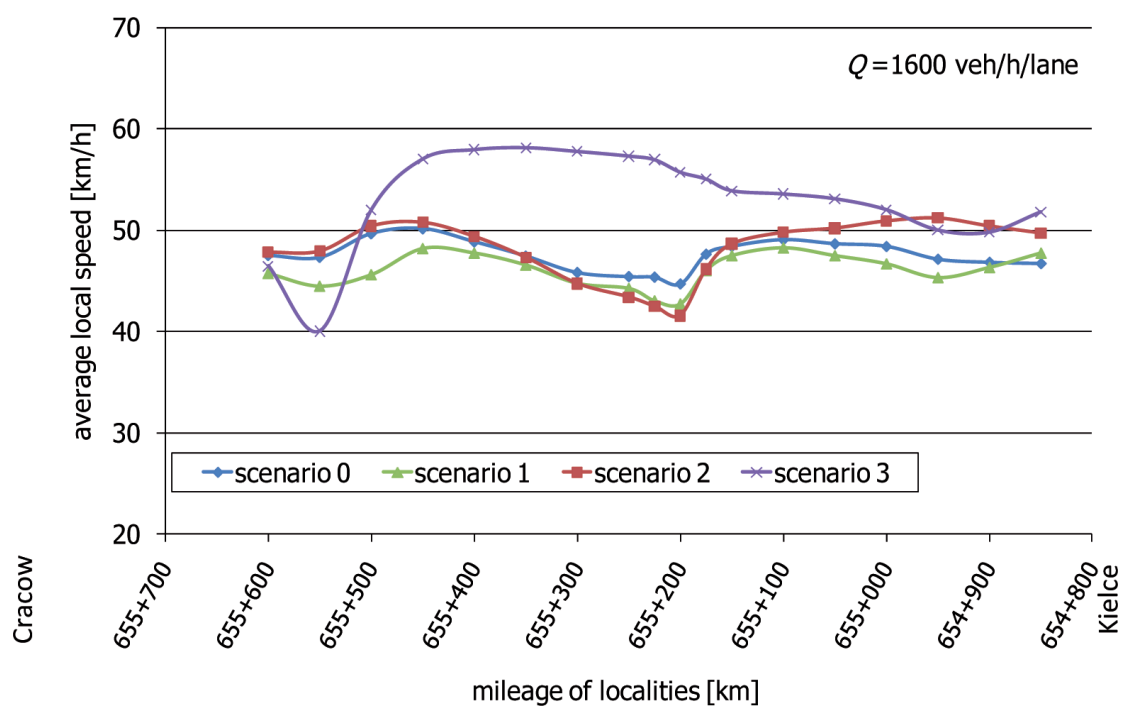

Fig. 3. Profiles of average local speed on Cracow - Kielce direction for each scenario, with traffic volume of $1,600 \mathrm{veh} / \mathrm{h} / \mathrm{lane}$.



Fig. 4. Differences in the values of average travel speed, depending on traffic volume for each scenario as compared with scenario 0 . 
Next the delays when passing the investigated road section were analysed. The delays define the amount of time lost by each vehicle passing through the given road section compared with the time of passing the section at the speed in free flow. The delay is the extra time needed to pass the locality, including any traffic disturbances appearing over the built-up area length, e.g. intersections, driveways and traffic volume.

Fig. 5 illustrates the results of simulation research concerning the delays. They show the delay in a particular cross-section during passing, accruing from the section beginning for each scenario on both directions, with traffic volume of 1,600 veh/h/lane. The biggest time delays are definitely those for the design with no access control and no additional multifunctional median lane. For the other scenarios, the delays after the analysed section was passed are comparable, the differences are ca. $1.5 \mathrm{sec} / \mathrm{veh}$.



Fig. 5. Variability of delays over the section length for each scenario in both directions, with traffic volume of $1,600 \mathrm{veh} / \mathrm{h} / \mathrm{lane}$.

In driving over the analyzed section of ca. $800 \mathrm{~m}$ - depending on the driving direction and the solution of surroundings service the driver's average delay is $5 \div 20 \mathrm{sec} / \mathrm{veh}$, depending on the actual traffic volume.

The most significant delays in passing through the analysed section are for scenario 1 , irrespectively of the actual traffic volume. Scenario 3 turned out to be the most favourable, wherein disturbances occur only within the intersections on the built-up area ends. Average delays for this scenario range within $4.8 \div 15.7 \mathrm{sec} / \mathrm{veh}$. The analysis of the differences in delay values as compared with scenario 0 (Fig. 6) allows us to state that for the scenarios with access control and with an additional multifunctional 
median lane (scenarios $0,2,3$ ) a change in traffic volume has a minor impact on such delays. It is the effect of lack of disturbances caused by vehicles turning left.

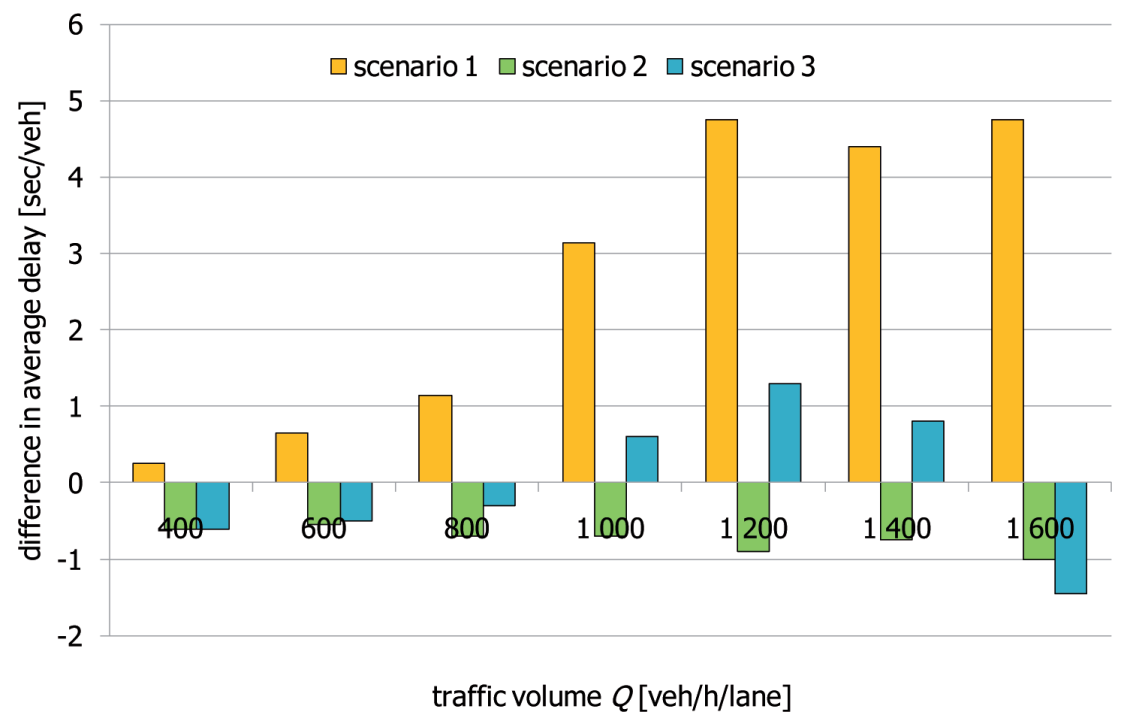

Fig. 6. Differences in the values of average delays, depending on traffic volume for each scenario as compared with scenario 0 .

Another possible measure of traffic performance is the share of platoon traffic. Intersections, numerous residential and commercial driveways, and the resulting traffic disturbances on the major road - (these) are factors which easily induce formation of vehicle platoons. Platoon traffic formation is affected by the length of a section with speed limit, as well as by density of access points - on two-lane sections, because overtaking manoeuvres are impossible. When analyzing the platoon traffic, it was assumed that whenever the time interval between following vehicles is less than $3.6 \mathrm{sec}$, they are moving in platoon traffic.

When driving over a model section of a small length (ca. $800 \mathrm{~m}$ ), the platoon traffic is dependent mainly on the traffic volume on the direction of the major road. Since there are few residential driveways, and since there is an additional multifunctional median lane, the access points have but minor effect on platoon traffic share.

Variations of platoon traffic share for each scenario of cross-section design and the volume of $600 \mathrm{veh} / \mathrm{h} / \mathrm{lane}$ and 1,600 veh/h/lane are shown in Fig. 7. Irrespectively of the actual volume and driving direction, differences in platoon traffic share for various scenarios are only minor. After driving ca. $300 \mathrm{~m}$ from the intersection, the platoon traffic percentage is stabilized accounting for ca. $80 \%$, since there are no major factors which would affect the travel conditions. Average share of platoon traffic for the volume of $600 \mathrm{veh} / \mathrm{h} / \mathrm{lane}$ accounts for $50 \%$, while for the volume of $1,600 \mathrm{veh} / \mathrm{h} / \mathrm{lane}$ there is a growth in this value to $90 \%$. 


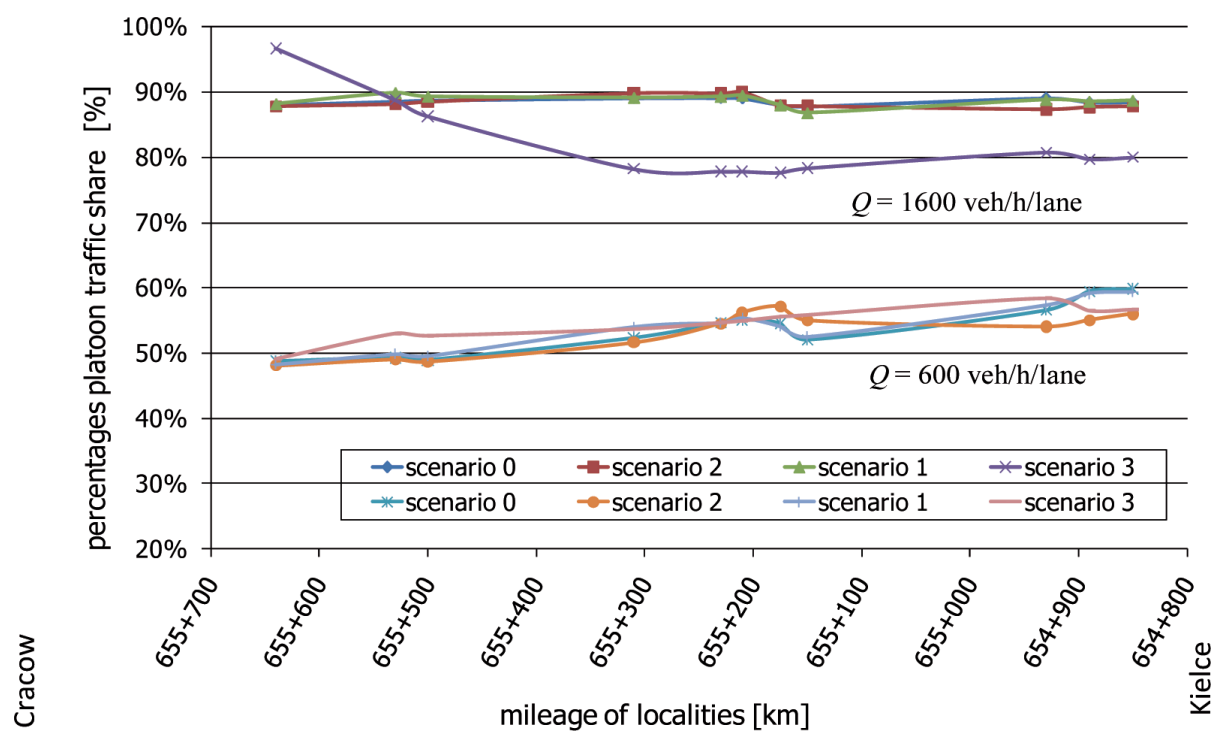

Fig. 7. Variations of platoon traffic share over the analyzed section length on Cracow-Kielce direction for each scenario, with traffic volume of $600 \mathrm{veh} / \mathrm{h} / \mathrm{lane}$ and $1,600 \mathrm{veh} / \mathrm{h} / \mathrm{lane}$.

The difference in average percentages of platoon traffic between the scenarios for different volumes is insignificant. On the basis of these data it can be stated that what affects platoon traffic share is the distribution and type of access points over the section length, as well as the traffic volume they generate, rather than the mode of the area surrounding service. It can be seen that with traffic volumes up to $800 \mathrm{veh} / \mathrm{h} / \mathrm{lane}$ the biggest share of platoon traffic is for scenario 3. The situation in this case changes for volumes over $1,000 \mathrm{veh} / \mathrm{h} / \mathrm{lane}$, when platoon traffic share is the smallest, which is related to the effect of intersections on the ends of the section (platoon traffic dispersion after the intersection is exited) (Fig. 8).

Table 1

Measurements of effectiveness for various scenarios of road network modifications - results of simulation.

\begin{tabular}{|c|c|c|c|c|c|c|c|c|c|c|c|c|}
\hline \multirow{3}{*}{$\begin{array}{c}\text { volume } \\
\text { [veh/h/lane] }\end{array}$} & \multicolumn{4}{|c|}{ average travel speed $[\mathrm{km} / \mathrm{h}]$} & \multicolumn{4}{|c|}{ delays [sec/veh] } & \multicolumn{4}{|c|}{ share of platoon traffic [\%] } \\
\hline & \multicolumn{4}{|c|}{ scenarios } & \multicolumn{4}{|c|}{ scenarios } & \multicolumn{4}{|c|}{ scenarios } \\
\hline & 0 & 1 & 2 & 3 & 0 & 1 & 2 & 3 & 0 & 1 & 2 & 3 \\
\hline 400 & 58.9 & 58.2 & 61.4 & 61.6 & 5.5 & 5.8 & 4.9 & 4.9 & 54.0 & 54.0 & 52.5 & 55.0 \\
\hline 600 & 57.7 & 56.8 & 60.1 & 59.9 & 6.7 & 7.4 & 6.2 & 6.2 & 64.0 & 65.5 & 63.5 & 66.0 \\
\hline 800 & 55.9 & 54.7 & 58.4 & 58.1 & 8.1 & 9.2 & 7.4 & 7.8 & 73.0 & 74.0 & 72.5 & 73.5 \\
\hline 1000 & 54.5 & 52.7 & 56.8 & 56.8 & 9.4 & 12.6 & 8.7 & 10.0 & 79.0 & 81.5 & 75.5 & 79.0 \\
\hline 1200 & 52.9 & 49.9 & 55.1 & 55.5 & 11.3 & 16.0 & 10.4 & 12.6 & 84.0 & 85.5 & 83.0 & 82.5 \\
\hline 1400 & 51.0 & 47.5 & 53.1 & 54.9 & 13.5 & 17.9 & 12.7 & 14.3 & 88.5 & 88.5 & 88.0 & 85.0 \\
\hline 1600 & 48.8 & 46.5 & 50.6 & 54.5 & 16.8 & 21.5 & 15.8 & 15.3 & 91.5 & 91.0 & 92.0 & 86.0 \\
\hline
\end{tabular}




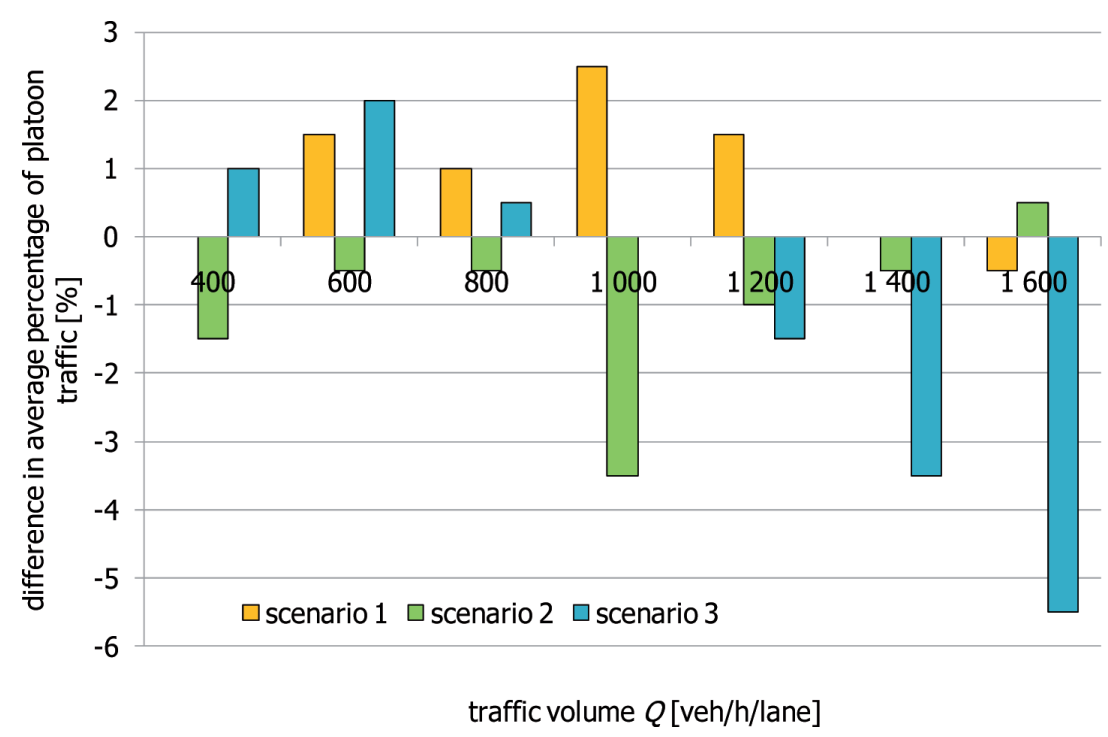

Fig. 8. Differences of the values of average percentage of platoon traffic depending on the volume for each scenario as compared with scenario 0 .

\section{MODIFICATION OF ROAD SURROUNDINGS SERVICE BY USING ADDITIONAL MULTIFUNCTION MEDIAN LANE}

One of the main factors affecting traffic performance when passing through localities is the relation between turns and development, the relation which disturbs through traffic over built-up section. Consequently, an analysis was made of a cross-section modification from two-lane with paved shoulders (scenario 1) to a section with a multifunction median lane (scenario 0) (Figs 1 and 9).



Fig. 9. Cross-section with additional multifunctional lane [16]

The cross-section with an additional multifunctional lane on roads passing through localities is usually introduced together with traffic calming measures (narrowed sections, traffic islands in the middle, lane staggering). Initial, standard $14.0 \mathrm{~m}$ wide paved part of the road allows to construct two $3.50 \div 3.75 \mathrm{~m}$ wide lanes and $3.00 \div 3.50$ m wide median lane (Fig. 9). Median lanes are used as a space where vehicles wait for both left turning and joining the traffic. Mid-islands on median lanes prevent left turning 
manoeuvres on this lane and, additionally, function as a kind of refuge enabling pedestrians to crosswise. Cross-section reconstructions and another use of paved shoulders requires widening of cross section top to add facilities for pedestrian traffic. The above design is gaining popularity and has been tested to assess its safety and traffic efficiency [16].

Replacing the cross-sections with bituminous shoulders with cross-sections with multifunctional median lane resulted, on six analysed road sections, in decreasing the number of collisions by ca. $29 \%$ and their casualties by ca. $31 \%$. The safety improvement resulted from, for example, reduction of values of speed quantile $85 \%$ amounting to $2.3 \div 12.7 \mathrm{~km} / \mathrm{h}$. Moreover, the number of potential collisions of vehicles turning from the major road and vehicles heading straight (has) decreased as well (cases of driving into the back of a vehicle) [16].

The use of an additional multifunction median lane resulted in better traffic performance due to fewer disturbances on the major road. For the analyzed section, starting from the traffic volume of ca. 1,000 veh/h/lane there was a decrease in average delays by ca. $5 \mathrm{sec} / \mathrm{veh}(33 \%)$ as compared with the scenario with such lane not provided (scenario 1 - before the cross-section modification) (Fig. 10).

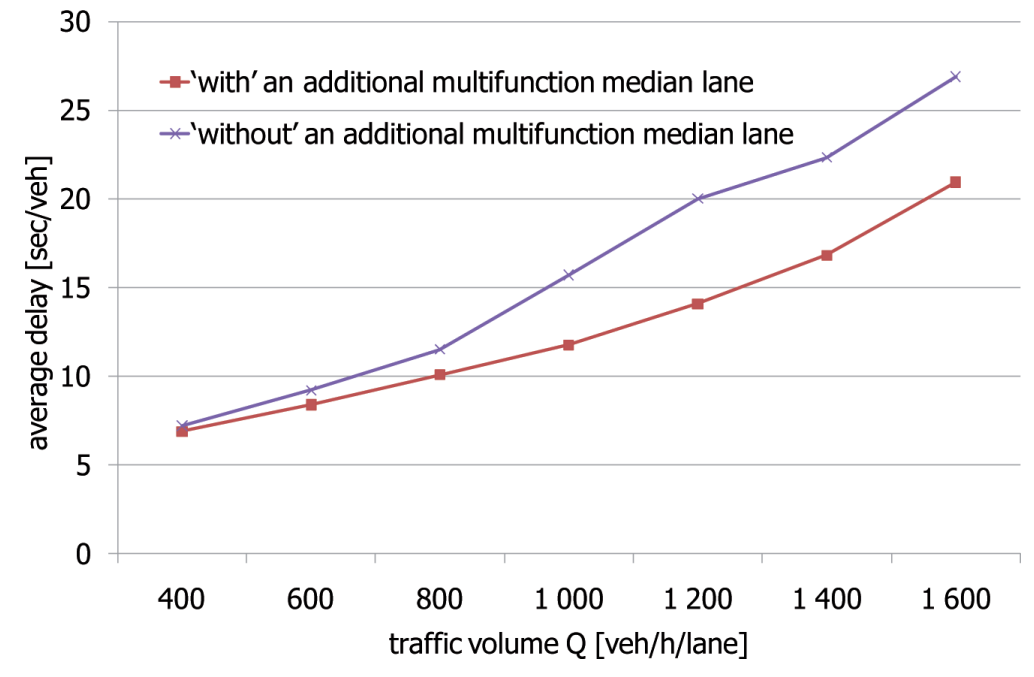

Fig. 10. Impact of traffic volume on delay depending on traffic volume for a road cross-section 'with' and 'without' an additional multifunction median lane.

\section{THE RESULTS}

On the basis of simulation research, the following conclusions were drawn:

- Using service roads linked with major road by means of two intersections located on the section ends (scenario 3) results in a substantial improvement of traffic 
performance. It is due to lack of disturbances occurring when driving over the section between two intersections. At the same time, high average travel speeds are achieved, over $53 \mathrm{~km} / \mathrm{h}$, irrespective of traffic volume, as well as low average delays (up to $20.4 \mathrm{sec} / \mathrm{veh} / \mathrm{km}$ ).

- A single intersection in the section centre servicing the entire local traffic (scenario 2) gives no rise to any substantial improvement of travel conditions, such intersection, resulting in vehicle platoons formed and in a decrease of average local speed.

- Modification of road surroundings service is of insignificant effect on platoon traffic percentage, irrespective of traffic volume. Both the type and location of access points in small communities determine the level of increase in the share of platoon traffic in a stream of vehicles alongside their length.

- Significant effect of cross-section type on traffic performance. With the cross-section modified from two-lane with paved shoulders to a cross-section with an additional multifunction median lane, there is a decrease in average delays by ca. $5 \mathrm{sec} / \mathrm{veh}$, i.e. by $33 \%$ (starting from $1,000 \mathrm{veh} / \mathrm{h} / \mathrm{lane}$ ).

- Apart from the analyses of road traffic performance, the authors also investigated road safety using the "before and after" method for sections with a modified cross-section, i.e. after a multifuctional median lane was added. On the basis of the analyses on six sections modified by the multifunction median lane added, it was found that the number of crashes and their victims was substantially reduced. It is related to the simultaneous drop of speed in free flow as compared with the section with paved shoulders.

\section{Conclusions}

On the basis of the analyses of the effectiveness of various types of service of road surroundings on suburban road sections the following conclusions can be drawn:

- models of estimation of traffic performance presented in the study indicate that any reconstruction of a road system accumulating over 15 residential driveways to one cross-section per kilometre of the road in passing through small localities improves traffic performance and reduces accident risk [1];

- use of a multifunctional median lane, particularly in cases where traffic volume exceeds $1,000 \mathrm{veh} / \mathrm{h} / \mathrm{lane}$ in the cross-section leads to a marked improvement of road traffic performance and traffic safety. Therefore, such modification shall be promoted, especially when space required to construct service roadways is not available;

- traffic performance and safety are most affected by the length of road section with buildings. For that very reason, the proportion of such sections in the total road network should be reduced by promoting housing development along local road networks; 
- analysis of traffic performance shows that on road sections with access control missing it is most advantageous to provide for such control by constructing service roads connected to the road by intersections located on section ends. Should providing a full control be impossible, it is recommended to use a section with multifunction median lane.

- The solution that is most economically effective and applied most frequently in Poland is modifying road cross-section by an additional median lane. Construction of service roads, despite some advantages, is undertaken only in cases when it is enforced by road technical condition standard.

\section{Aknowledgements}

The paper presents the results of research conducted at the Chair of Highway and Traffic Engineering of the Cracow University of Technology in the framework of the research project: The decision support tools in the design and reconstruction of bypasses and roads passing through small towns (in progress 2010-2013). The researches are funded from budget resources of The National Centre for Research and Development.

\section{REFERENCES}

1. M. Tracz et al., Identification and Predicting of the Scope of Environmental Effects of Vehicle Traffic on the Road Passing Through Small Communities - Research Report No R10 008 02, Ministry of Science and University Education, Chair of Highway and Traffic Engineering, Cracow University of Technology, 2009 (not published).

2. HBS 2001, Handbuch für die Bemessung von Straßenverkehrsanlagen. Forschungsgesellschaft für Straßen- und Verkehrswesen e.V, Köln 2001.

3. HCM 2010, Highway Capacity Manual 2010, Transportation Research Board, National Research Council Washington, D.C. 2010.

4. W.L. Eisele, W.E. Frawley, Estimating the Impacts of Access Management with Micro-Simulation, $6^{\text {th }}$ National Conference on Access Management, Kansas City, 2004.

5. K.F.M. Aronsson, K.L. Bang, Factors Influencing Speed Profiles on Urban Streets, $3^{\text {rd }}$ International Symposium on Highway Geometric Design, TRB, Chicago 2005.

6. K.F.M. Aronsson, K.L. BAng, Influence on Vehicle Speed Profiles of Interactions with other Road Users, Association for European Transport and contributors, 2006.

7. M.D. Pawlovich, W. Li, A. Carriquiry, T. Welch, Iowa's Experience with 2-Lane to 3-Lane Conversions, $3^{\text {rd }}$ Urban Street Symposium, Seattle, Washington, 2007.

8. F. Galante et al.,Traffic Calming Along Rural Highways Crossing Small Urban Communities: Driving Simulator Experiment, Accident Analysis \& Prevention, 42, 1585-1594, 2010.

9. F. Bella, Driving Simulator for Speed Research on Two-Lane Rural Roads, Accident Analysis \& Prevention, 40, 2008.

10. S. Gaca, M. KIEć, Models of Traffic Flows With Speed Limits, Archives of Transport, PAN, 17, 15-34, Warsaw 2005. 
11. K. Knapp, K. Giese, T. Welch, Comparison of Simulated Average Arterial Travel Speeds Along Four-Lane Undivided and Three-Lane Roadways with Similar Traffic Flow and Access Density Characteristics, 81st Annual Meeting TRB, 2002.

12. A. Al-Kaisy, S. Karjala, Indicators of Performance on Two-Lane Rural Highways - Empirical Investigation, Washington, D.C., 2008.

13. VISSIM 5.10 User Manual, PTV AG, Germany 2008.

14. K. Herda, K. Skraba, The impact of traffic flow through built up areas on traffic performance. MSc thesis, Politechnika Krakowska, 2011 (in Polish).

15. www.geoportal.gov.pl

16. S. Gaca, M. Tracz, Recent Developments in Highway Geometric Design in the Reconstruction of the Polish Road Network - Country Report. $4^{\text {th }}$ International Symposium on Highway Geometric Design. Valencia, 2010

Remarks on the paper should be sent to the Editorial Office

no later than December 31, 2012
Received March 15, 2012 revised version September 01, 2012 